\title{
Alternativeness of Attitudes to Formation of the Marketing Technologies of Construction Business Strategic Development
}

\author{
Anna Mihailovna Kulik \\ Ludmila Vasiljevna Usatova \\ Natalja Alekseevna Kaluckaja \\ Natalja Nikolaevna Peresypkina \\ Marina Aleksandrovna Ameljchenko
}

Belgorod National Research University, 85, Pobedy St., Belgorod, 308015, Russia

Doi:10.5901/mjss.2016.v7n1p70

\begin{abstract}
Marketing in a company is one of the main and essential components in its functioning. Marketing in its life activity is oriented to the market processes. For commercial organizations, the composition of tools, techniques and methods of marketing would seem obvious, but its use is provided by individual market strategy of the company. Commercial organizations for the effective use of marketing techniques and tools must have a certain human resources, marketing specialists. However, in the regions there is both a lack of personnel, and the experience of use of marketing in a number of industries. Development of marketing technologies and marketing technologisation is being possible in recent years, it should greatly facilitate the marketing work in the company and contribute to obtaining the desired result. Therefore, the main aim of the work is to provide a variety of approaches to the formation of marketing technologies of business strategic development
\end{abstract}

Keywords: marketing technologies, targeting, flexibility, formalization

\section{Introduction}

Use of marketing by organizations in different sectors has its own peculiarities. Organizations of the building complex also have its own characteristics. There are many companies in the construction industry, they represent different areas of business, a high staff mobility, attachment to the territory, where construction is in progress. One of the main conditions for effective activity of the construction complex organizations is the active use of marketing tools to achieve its social and economic objectives. We have to admit that the issues of technologisation of marketing activities in general, as well as taking into account organization of regional construction complexes have been hardly developed in domestic and foreign literature, which determined the actuality of the research topic.

\section{Method}

The research method is based on the main provisions of the theory of marketing, works of domestic and foreign scientists relating the issues of technologisation of marketing activities, the objective economic laws, dialectical and systemic approach, considering the phenomenon in the process of their development and in the interrelation. In the course of the research we examined the decisions of the Government of the Belgorod region concerning the construction complex, as well as theoretical works on various aspects of the problem. In the process of writing of the article the author used scientific methods, general scientific principles of dialectical development and system approach, models of technological push, the "pull by market" model, a combined model. The information was processed using information technologies.

\section{Results}

\subsection{Study of the theoretical approaches to the classification of the marketing technologies}

Marketing activity in general, as well as any marketing technology, has a target orientation. Setting and achieving the 
objective of marketing activity creates conditions for the formation of the concept, as a synergetic and customer-oriented philosophy of conducting business by the organization or person [1]. Selection of a marketing concept, which means marketing technology, depends on the profile of construction and the scope of construction organizations. While studying the theoretical approaches to the classification of marketing technologies and practical experience of their use, the following and most popular of them may be emphasized: targeting (definition of objectives), segmentation, marketing researches, positioning, analysis and forecasting. Targeting (target setting) as the marketing technology allows identifying according to certain parameters a target audience among total number of consumers, for which a particular company's product is meant and at which this or that advertising of this product is addressed. Segmentation as a marketing technology means a work relating split of the market into certain separate segments for research and study of consumers' demand, consumers' attitudes to certain products [2]. Marketing research is a marketing technology, the aim of which is to create an information-analytical base which provides making of marketing decisions and helps to reduce the uncertainty in the field of marketing and making effective decisions on marketing problems [3]. Positioning is a marketing technology, allowing the products of the companies using certain tools to take a more advantageous position on the market than the position of the competitors' goods. The analysis (including analysis of sales) - is a marketing technology, which includes activities concerning the research and study of market of goods and services, the availability and level of demand for certain products, goods, services, the study of the pricing policy on the market in dynamics, obtaining data and determining consumer attitudes to certain types of goods in order to increase the demand for the company's goods. Forecasting is one of the most important marketing technologies and represents the techniques and methods of marketing research in order to assess the prospects of the market, possibilities of its development, tracking of the dynamics of prices and their trends of their changes for the period of forecast. Forecasting may be short-term, mediumterm and long-term. [4] In general, summing up the above, it should be noted that the marketing technologies play a key role in achieving by the regional construction complex and, in particular, the construction companies of the region, their objectives, qualitatively and quantitatively satisfaction of the growing needs of consumers in construction products, changing and updating the architectural and construction look of the region in whole. Representing in a point of fact the decomposition of the marketing process at a stage and operations, with the subsequent regulation of the procedures and operations, the technologization of marketing activity in the construction activity of the region makes it possible to solve the problems emerged in this field most efficiently. Namely to study the consumer, his needs; to explore the motives of his behavior on the market; to analyze the market of construction products; to explore the product; to analyze forms and channels of distribution of products; to analyze the sales volumes of construction enterprises; to examine the competitors, to determine the shape and the level of competition; to examine the advertising activity; to determine the most effective ways to promote the construction products on the market; to study "niches" of the construction market of the region, or the forms of industrial or commercial activities in which the construction company has the best opportunities to realize their competitive advantages to increase profits and sales volume.

\subsection{Definition of the marketing technologies group}

Summing up the groups of approaches to the formation of marketing technologies of strategic business development for each of them, the following groups of technologies can be specified: weakly formalized techniques that do not use standard elements and that are used for small marketing projects, as rule innovative ones. Such approaches include the so-called original solutions of various problems of marketing, which are not previously solved. Therefore, the use of formal marketing technologies is not possible. Rigidly formalized technologies recommended for use in medium, large and very large marketing projects. Predictability is their main requirement. It is recommended to use flexible technologies for small or medium-sized marketing projects in the case of changing conditions and market uncertainties. The marketing team must be qualified and well-regulated and formal, and creative at the same time, and customers take part in the realization of the project. You can try to assess the possible level of flexibility of the technology and possibilities of its formalization. The technology can be both flexible and easily-formalized, but can also be difficult to formalize. That is, depending on the range of activity, the type of product, the target audience, one or the other technology can be used without restriction or its use may be limited by the market or product. We introduce the concept of flexibility (versatility) of the technology. Flexible marketing technologies are technologies which have the property of flexibility. In technology, the flexibility is a characteristic that reflects the system's ability to adapt to internal and external actions, and supports the required level of functioning efficiency. Therefore, the most important characteristics of achievement of an appropriate level of flexibility are usually called modularity, systemacity, variability, informativeness. That is, almost everything that was listed in the previous paragraphs can be applicable to marketing technologies. The more there are modules (elements) the more flexible the technology is, the more variants of considered technology there are, the more flexible the 
technology is, etc..

\section{Discussions}

\subsection{Definition of flexibility and its forms}

Some researchers believe that the flexibility can be operational and strategic. In our case, the operational one depends on the internal organizational and technological structure of marketing services at its permanent professional functions, and strategic one is connected with the provision of efficiency of marketing technologies.

In connection with the structure of the marketing techniques and the following forms of flexibility can be supposed:

- flexibility of marketing solutions;

- Flexibility of the marketing process;

- Flexibility of the organizational structure of marketing service;

- Information flexibility.

Thus, depending on the nature of the market and its condition, various levels of variability of the technology can develop and act in the company: "stable", "productive", "changeable".

The authors call "Stable" the technology subject to change during the entire life demand for goods.

The technology used unchanged for several generations of products production, which differ from each other by improved features and range of applications is considered "Productive".

The process often changing technologies is called "changeable".

This example does not contradict the notion of flexibility suggested by the author.

The engineers give their own interpretation of the flexibility. Sokolov V.G. and Smirnov V.A. define it as "the ultimate ability of the system to the structural, technological, organizational and economic restructuring".

The famous scientist, mechanical engineer V.N. Vasilyev believes that describing the integration of any process, as a union under a single specific functions management system, while maintaining their autonomy, and comes to the conclusion that it is possible in the organization of the process of the module-block principle. When each block develops independently, in his opinion, it helps the development of the flexibility in the process. The same thing is seen in marketing, where the use of block-modular principle is not only possible, but natural. Considering the "flexibility" category Bleherman M.H. [5] writes that in the scientific literature there are various descriptions of its many forms, therefore a single approach to classification of flexibility is needed. M.H. Bleherman suggests presenting "flexibility" as a kind of an ordered collection of different types of flexibility.

In our case, with regard to marketing technology, "block-modularity" may be provided by clearly formed patterns, which can also develop independently, but a set of different types of flexibility is made up of components typical for marketing.

Clarifying the category of "flexible marketing technology", a complex approach which would take into account all its aspects, forms, criteria and indicators is worth using. This becomes evident by studying marketing techniques, in terms of flexibility. After analyzing the existing forms it can be concluded that they (the forms of flexibility) can be implemented in the form of a four-level scheme (Fig. 1).

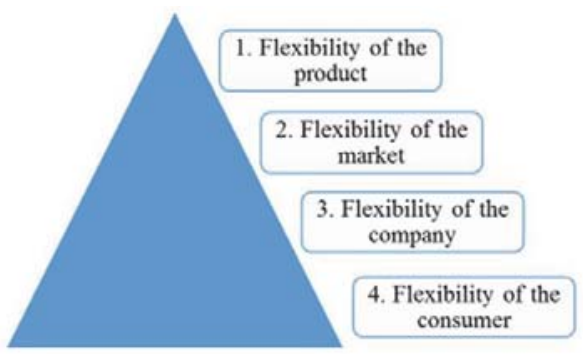

Figure 1. Levels of flexibility of the marketing technology

A variety of forms of flexibility is so great that, in spite of the importance of this parameter, it is still poorly studied, even in technique, so representation of the scheme, which would include all forms of flexibility in marketing, is impossible. The 
proposed scheme has the character of classification, and reflects the basic forms of flexibility of the marketing technology.

You can imagine the first level of flexibility by the flexibility of the product. What can inhibit the introduction of a technology is the nature of the product. There are different classifications of products (let's denote i-th type of a product by the symbol Xi), to a large extent the determinative nature of the marketing activities. With the development of marketing technologies there are new methods that lead to product flexibility increasing. This flexibility is characterized by a number of methods, ways, variants, and in fact - the technological patterns that can be applied while forming technology (let's denote a number of methods by the symbol Y), relating to a particular product. The flexibility of the product can be fixed in the form of a range, in which marketing methods used in marketing for this product are listed:

$\beta h=f(U 1, U 2, U 3, \ldots U m)$, where $m$ is the number of possible marketing methods used for this product.

The second level of flexibility can be defined in terms of the flexibility of the market. The market flexibility can be changed by changing the flexibility of the product - the first level of flexibility. Formally the market flexibility can be represented in the form of $\mathrm{Xi}$ range, listing all possible product modifications created and realized in the market: $\beta y=f$ $(\mathrm{X} 1, \mathrm{X} 2, \mathrm{X} 3 \ldots \mathrm{Hn})$, where $\mathrm{n}$ is the number of modifications of the product in the market.

The third level of flexibility is provided by the flexibility of the company. Different processes run simultaneously in the system marketing, which can also be classified according to various criteria.

There are analytical, product, price, communication, marketing, and others processes. The flexibility of the company can be characterized by an average flexibility of the organizational structure, products; it reflects the overall company's working efficiency. The percentage of employees of marketing service in the total number of the company acts

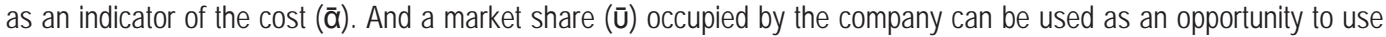
the entire spectrum of marketing techniques.

Formally, the company's flexibility can be written as follows: $\beta k=f(\beta h, \beta y, \bar{\alpha}, \bar{u})$, where $\beta x-$ is an average flexibility of the product; $\beta y$ - is an average flexibility of the market ; $\bar{\alpha}$ - is an average percentage of the employees of the marketing service of the total number of the company; $\overline{\mathrm{u}}$ - is the average share of the company. flexibility.

The fourth and last level of flexibility - is the flexibility of the consumer. It includes all of the above levels of

Formally, we can write the flexibility of marketing technology as follows:

$\beta=f\left(\beta_{x}, \beta_{y}, \beta_{k}, \beta_{\Pi)}\right.$

\subsection{Flexibility and possibility of formalization for marketing technology}

Based on empirical research with the use of expert analysis, the possibility of formalization technology, which is a fixed set of statements that any technology is divided into stages, operations and patterns, as well as in respect to our case - is the ability to specify appropriate technological patterns for further duplication in the construction industry. If we take the high opportunity of technology duplication for $100 \%$, it is possible to allocate the share of replicated technology (a number of patterns of the total number that can be duplicated). It is suggested to assess these characteristics with the help of usual scores, the degree of manifestation of each characteristic in the technology: "5" - the technology is fully formalizable and is used for any of the products and markets; "4" - if $2 / 3$ of operations are formalized, and there are nonessential limits of its use; "3" - a half the operations are formalized and limited in scope; "2" - 1/3 of operations are formalized and have very significant limitations; "1" - creation of templates and limited exposure are impossible . However, to facilitate the application of the method, we use the categories: high, medium and poor.

Let's consider the flexibility and possibility of formalization for marketing technologies necessary for further classification of technologies (Table. 1).

Table 1. Flexibility and possibility of formalization for marketing technologies

\begin{tabular}{|l|l|c|}
\hline Name of group of technologies & Flexibility of use & Formalization possibility \\
\hline Technologies of marketing researches & High & Medium \\
\hline Management of marketing complex on the basis of CRM-technologies & Limited with program features & \multicolumn{1}{c|}{ High } \\
\hline Guerrilla marketing technology & Limited with type of product and customer & Medium \\
\hline Viral marketing technology & Limited with type of product and customer & \multicolumn{1}{|c|}{ Medium } \\
\hline Trade-marketing and merchandising & Limited with planning quality and application field & High \\
\hline Network marketing technology & Limited with application field & High \\
\hline Integrated marketing communications & High & Poor \\
\hline Brand technology. Rebranding & High & Poor \\
\hline
\end{tabular}




\begin{tabular}{|l|l|l|}
\hline Cross-marketing technologies & High & Medium \\
\hline Marketing technologies of the call-center & Medium, limited with personnel skill level & Medium \\
\hline Marketing internet technologies & High & High \\
\hline Mobile marketing technologies & Poor & High \\
\hline Product placement & High & Poor \\
\hline Direct marketing & Poor & High \\
\hline Technology of an exhibition activity of the enterprise & Poor & High \\
\hline
\end{tabular}

Next, let's consider the intersection of the areas of the specified characteristics, for the crossed marketing technologies (fig. 2).

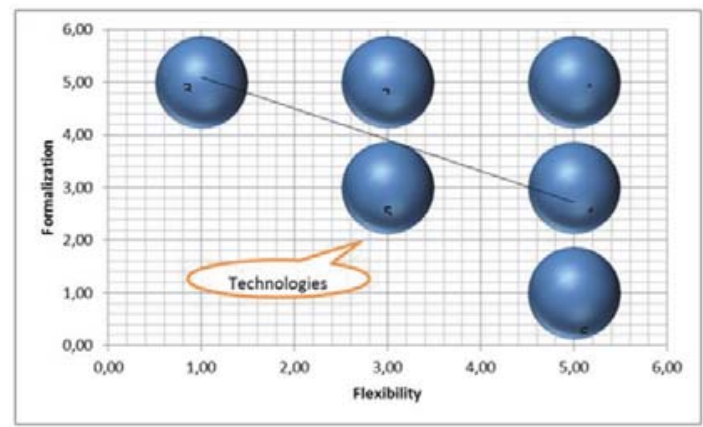

Figure 2. Classification of the technologies according to flexibility of the use and possibility of formalization.

Thus, the considered technologies can be divided into 6 groups:

The first group of technologies: Technology marketing researches and marketing internet technologies - have a high index of both on the flexibility and the possibility of formalization, so can be used in all industries.

The second group of technologies: Management of marketing complex on the basis of CRM-technologies, Trade Marketing and Merchandising, Network marketing technology- are limited in application field, limiting the possibility of formalization.

The third group of technologies: Mobile marketing technology, direct marketing of the company's exhibition activities - technology of limited action (the author included mobile technologies in this group, in connection with the preparation of the law on limitation of their actions).

The fourth group of technologies: Cross - marketing technology, Integrated Marketing Communications - the possibility of technology formalization is partly limited by multi-directional limitations, such as interrelations with counterparties, the possibility of an integrated approach, and others.

The fifth group of technologies: Guerrilla marketing technology, viral marketing technology, marketing technologies of the call center - the technologies are applicable in the case if the company is working on a large emerging market.

The sixth group of technologies: Brand technology. Re-branding, Product placement - use of the technologies is limited by the type of the product and it is difficult to formalize and requires creative approach.

Applicability of marketing technology to a particular sector of industry or company depends on flexibility and its formalization possibility. It should be noted that the formalization is always incomplete. It is impossible to formalize the creative component, so the author believes that each technology has both a formal and creative part. The combination of creative and formal parts in each technology is different, the higher the flexibility, the higher is formalized part of the technology, the less flexibility, the more creative component the technology has and requires an individual solution.

At the present stage of the development of domestic regions construction complex is one of the fastest growing industry economic complexes of the national economy. The effective activities of the companies of the construction complex at the regional level are the main and decisive condition for the expansion and qualitative improvement of housing and industrial construction. However, without significant changes in the management organization system, and especially the use of marketing tools in the activities of construction companies it is impossible to fully satisfy the growing market needs in the products of the construction industry, to provide renewal of architectural and building appearance of cities and towns. The transformation of the regional construction complex into a dynamically developing, high-tech, efficient and competitive sphere, able to integrate into the world market of construction products and building materials 
production industry makes construction companies revise approaches to the organization of marketing activities and use the modern marketing technologies.

It is necessary to recognize the fact that under the modern market conditions the marketing activities of companies in the construction complex of the region obtain new meaning and content. It is based on the fact that the market of construction products is unique, in addition, it has been formed very recently. Summarizing the views you can select the traditional approach to the "construction marketing" definition. Construction marketing - is a permanent system of accumulation of objective information, its processing and exchange between all structural subdivisions to provide sustainable, predictable and managed sales process of the construction services complex and construction industry products [6].

According to U.K. Sushko [7] marketing in the construction sector combines a number of types of activities (in the Belgorod region - there are three types of activities), and in the final form it is a complex system of market analysis organization, production and sales of products, as well as services of the construction industry, aimed at achieving satisfaction of the needs of specific groups of consumers, with the help of the concerned cooperation between the state and the market, and on this basis obtaining of the profits and competitive advantages by economic entities. In our view marketing in construction practice is first of all a system of interrelated and complementary marketing technologies enabling the construction company to efficiently satisfy the needs of consumers and to achieve specific social and economic results.

\subsection{Specific features of construction as a type of activity}

Considering the specifics of marketing technologizing in the regional construction complex it should be noted that it is first of all associated with the peculiarities of the construction as a type of activity. According to E.N. Kanysheva, these specific features of the construction as a type of activity are as follows:

- Construction products have territorial consolidation. When the fieldworks are finished, the tools and workers are moved to another site;

- The feature of both the life cycle and the long duration of the production cycle;

- Architectural diversity of residential as well as non-residential construction projects;

- The production process is significantly influenced by geographic, in particular climatic conditions;

- This is the most material intensive sector of the national economy, both according to volume and diversity of nomenclature of consumable materials, structures and equipment;

- Capital construction is tied to the local deposits of raw materials in all regions of the country;

- A wide range of construction products requires the establishment of a large number of enterprises, while complicating the complete set of construction sites.

According to many authors the specificity of construction products has a special influence on the formation of the features of marketing in the construction industry.

The construction industry is a whole range of goods and services. These are real estate items, which are offered both for the purpose of buying and selling, and for the purpose of the lease, for personal or public use. As the product finished buildings and constructions both of housing and civil and industrial purposes, building construction, building materials and mixtures, materials for the repair and decoration can be considered here. Construction products can be accompanied by a whole set of services for the development of real estate projects. Besides the above listed things, the concept of "construction products as a commodity" means a range of services of support of real estate items that are rendered for the entire period from construction to post-construction period.

Thus, the products in the construction industry can be considered in the marketing system as a commodity, beginning from its plan to actual implementation, and services in the form of support of construction products, and contractors' services. This significantly distinguishes the construction products from the goods of other industries, both of mass and serial production [8].

Exploring and analyzing marketing activities in the construction industry, characteristics of construction products as a commodity should be considered in more detail.

The author lists some of the features of production of a building complex [9], having, according to the author, the impact on the marketing technologization. It was found that the real estate market also has specific features that affect the promotion.

In the "life cycle" of construction products, in accordance with international standards, the researchers specify 11 stages ("quality loop"), which in relation to our products, are reduced to 9 generalized structural elements of the "life cycle" of production of the construction complex. From the above scheme Asaul A.N. makes the following conclusions: 
Firstly, we can state the interrelation of production processes, implementation and operation of the construction complex products. This fact obliges to display this interrelation during the formation of a management system.

Secondly, although the marketing events are used in the implementation phase, they are not completed. They can be on the contrary considered as the beginning of the process, in which the characteristics and the scope of the construction are set taking into account market conditions, market demand, competitive situation and product offering.

Another conclusion can be added to the above ones:

Third, all of these conditions have a direct impact on the technologization of the marketing process in the sphere of building production and are limitations, i.e., the specific features of the building complex products have a significant impact, both on implementation and on the work of the companies in this sphere.

Each of the characteristics of the products of the building complex complicates its successful operation on the market in comparison with the products of other industries. It affects the forms and methods of marketing, the choice of the used technologies and involves multiple aspects of marketing decisions.

\subsection{Classification of the construction products within the marketing technologies formalization}

Considering the classification of marketing technologies in terms of flexibility, for its effective and proper selection it is necessary to classify also construction products. Taking into account the opinion of E.V. Patsyuk, the following groups in the construction industry can be specified:

1. Building structures and materials:

1.1. Raw materials and semi-finished products.

1.2. Building structures and products.

2. Buildings and constructions of capital purposes.

3. Services of contractors and designers.

Nagapetiants N.A. believes that a company in the sphere is an industrial organization, the result of activity of which is a finished construction site, but it can not be regarded as a commodity, because at the same time it plays the role of "a promotional image element". Therefore, the company in the construction sphere is a symbiosis of the specific features of an industrial company, and the company providing various kinds of services.

Therefore, the orientation of marketing service in a construction company is primarily focused on the use of marketing techniques that create an effective system of collecting, processing and analyzing of marketing information, which will later allow making reasoned decisions.

As a result, we can say that the success of the use of marketing techniques, largely depends on the efficient work of the marketing (Service) department, in which both the understanding of economic processes taking place in the market and features of products and features of consumers should be reflected.

In such a company it is reasonable to organize marketing services with a flexible structure, and its leader must have the status of the Deputy Director (the President). business:

With regard to the contractor construction organization the researchers specify the following marketing areas of

1. Common marketing - held in order to emphasize the characteristics that can affect the company's financial results.

2. Research and analysis of the construction market - identifying priorities, dynamics, structure and tendencies of its development, the selection of the target audiences.

3. Marketing of construction projects - segmentation, research, analysis of real and specifying of potential consumers of the construction services, the study of the preferences of customers.

4. Technological construction marketing directed to materials and equipment (often considering innovations) assumes research, analysis and evaluation of the economic efficiency of the development, deployment and use of new construction materials and technologies in being built and planned sites.

5. Competitive marketing is designed to search competitive advantages, analysis of the competitive situation and the status of contractual relations, developing pricing policy.

6. And others.[10].

\subsection{Systematization of background and barriers of marketing technologization.}

Modern business environment requires every employer and a head of an economic entity to continually improve their management arsenal, the priority position in which is occupied by marketing technologies. It is a marketing tool that 
enables to decide the problems related to the creation, distribution and consumption of goods and services effectively, in general, to "stay afloat" in a rather turbulent market environment. Having the most creative component and variability marketing as a science and as a type of activity allows management personnel to construct the adaptive marketing technologies to solve any socio-economic problem of the organization.

One of the main marketing activities technologization areas is the introduction of technologies in the marketing process. The technologization follows from the fact that any marketing activity includes, besides the creative component, also activity bureaucratic or routine in its nature. Routine is not a management system, not a layer of specialists marketers, whose activities are governed by rules, but a certain group of operations performed by a specialist [11].

Such routine operations or procedures include:

- execution of actions that have clearly defined objectives, which can be built in a hierarchy, based on the company's objectives and marketing goals;

- adjustment and conforming to plan of the performed work;

- separation of routine procedures and differentiation of carried out works. Marketing technologies take place, as we have said above, only in cases when it is possible to divide the process into certain specific procedures;

- rationality, based on a scientific approach. Marketing technologies are based on rationalism and scientific knowledge.

Marketing activity is characterized by the contradiction between the creative initiative and a predisposition to rationalization of activity. In our opinion, one of the most typical barriers restraining technologization in general, should include:

1. Socio-cultural barriers related to the mentality of Russians, more tending to the creative activity.

2. Corporate and bureaucratic barriers when routine self-organization, tending to the process management, washes creative component of marketing activity.

3. Professional and educational barrier, which is determined by a lack of competent specialists of the Marketing Service.

It should be noted that while using the "technologization" concept the certain conditions should be observed:

- any marketing activity can be technologized, even if we consider marketing of a company with no competitors, which has increased demand, etc. and, as it would seem, which does not need marketing, then such company may use a minimum of technologies;

- all the components of the marketing process should be known, especially its construction and functioning, these components should be formalized and divided into stages, operations, activities and practices;

- $\quad$ each component must be described by a system of specific indicators, methods and techniques of the use and management.

Both marketing processes and the system of marketing tools are objects of marketing technologization.

At the same time, the modern approach to the implementation of marketing activities on the basis of marketing technologies requires observance of a number of general principles:

- practicability which consists in obtaining the expected results;

- specification of techniques and methods, which consists in the description and appearance;

- planning, the necessary element of which is the possibility of constructing the line of marketing activities of the components connected by the same logic;

- organization of the control of each element of marketing activities consisting in providing of the possibility of control;

- harmonization which consists in a combination of executive discipline and stimulation of creative activity of specialists;

- multifunctionality, taking into account a variety of methods and forms of elements of technology, combined with their unification.

Using the concept of marketing technologization helps to improve the effectiveness of management the economic entity [12].

Alekhina E.S. and Skrynnikova I.A. believe that marketing technologies are a well-considered marketing model, which includes the development, organization and carrying out of the entire set of marketing activities, which will provide for the company's decision of the set problems. Therefore the definition appropriate from the perspective of commercial company: marketing technologies - are a set of techniques and marketing decisions aimed at increasing of the degree of perception of the product by the consumer and increasing of the effectiveness of measures of its promotion in the market on the basis of the optimization of the resource potential of the company. [13]

Taking in consideration the above, it is possible to specify the three main view points for consideration for 
marketing technologies:

1. Research according to which marketing technologies are a systematic method of design, implementation and monitoring of the marketing process on the basis of its description and the results planning.

2. Formal - where technology marketing is a conceptual, systematic, objective, normative and invariant description of marketing activities.

3. Management, according to which the management of marketing processes, provide a system in the given parameters - quality of execution of work, their volumes, ensuring the integrity of activities, etc. [14].

Drawing conclusions, it can be noted that the above definition "marketing technique" is complicated and multifaceted and because of this, many researchers interpret it in their own way, so for some researchers it is a marketing tool, for others - a technique of its realization, for third ones it is a structure or model, for the fourth it is the system or set of elements for the realization of its goals. Of course, all the above judgments, and proposed variants of the definition of "marketing technology" are offered to comprehensively consider and discover the essence of marketing technologies. It should be noted that the many judgments concerning terminology, many-sidedness of the concept provide evidence of solving of the problem, which has essential or even critical impact on the future of marketing development.

The marketing technology is based on the idea of standardization on the one hand, and the process controllability on the other hand. In addition, the ease of its designing and the possibility to control it is due to its formalization. The researchers believe that the essence of the marketing technology consists in a constant feedback, ensuring the achievement of the set market objectives. In this context, the technology of setting goals becomes an important initial condition for the realization of the concept of marketing technologies. The marketing technology involves understanding of ways of achievement and predictability of the results. Marketing technologies are in fact characterized by the things that are typical for any other technologies, regardless of whether they are technical, administrative, educational, etc. Any technologies have their professional features. These features consist in what methods and tools they use and in what professional sphere they are realized[15].

Marketing technology also has its own features; it is possible to emphasize features of development of marketing solutions for a specific market, specific target audience, etc. Among them they are based on certain economic strategy. The order of the marketing stages, operations, techniques and actions can be in accordance with the target settings to obtaining of the planned result. Diagnostic procedures, which include indicators and tools for measuring of the results of activity should be considered as an integral part of marketing techniques [16].

\subsection{Traditional and technologized approaches to marketing}

Regulating nature of marketing technologies should be noted, the possibility of their use leads to introduction into effect a set of regulations rules for their application, which are obligatory for their implementation by the specialists. It leads to a refinement of official duties of the specialists of the marketing service, as a consequence to a change in the system of formal and informal relations in the marketing service and in the company, the restructuring of the structure of rights and responsibilities, and finally affects the relation of the actual power of the company. [17] Such features are important, while they are often not taken into account by the specialists and executive group. Therefore, an important property of individual marketing technologies, namely their uniqueness (lack of flexibility) is manifested in the fact that the same solution of identical tasks of marketing in each company is impossible. Solving of these problems is still made on their own, since their decision is carried out by different people, who have always different views, understanding and realization of the marketing process. Marketing technologies have their own personality that makes it difficult to use marketing techniques (Table. 2)

Table 2. Traditional and technologized approaches to marketing

\begin{tabular}{|l|l|}
\hline Traditional marketing & Technologized marketing \\
\hline $\begin{array}{l}\text { 1. The process is divided into the traditional stages and distributed } \\
\text { among the relevant marketing service subdivision }\end{array}$ & $\begin{array}{l}\text { 1. The process is divided into patterns, and is distributed between the } \\
\text { performers }\end{array}$ \\
\hline $\begin{array}{l}\text { 2. Knowing of the marketing process, corresponding to the stage is } \\
\text { required }\end{array}$ & $\begin{array}{l}\text { 2. Knowing of a part of the process falling under competence of the } \\
\text { contractor is required }\end{array}$ \\
\hline 3. The stages are mostly realized independently & 3. Patterns, that allow attracting the third party's contractors \\
\hline 4. The process is current & $\begin{array}{l}\text { 4. The process can be accelerated as a result of often repetition of the } \\
\text { pattern. Sharp fall of the temporary indicator of the exchange processes }\end{array}$ \\
\hline 5. The product is unique & 5. The product is standardized \\
\hline 6. Intuitive decision, intuitive obtain a results & 6. Predictability of the result \\
\hline 7. The result is limited by the specialist abilities & 7. The result does not depend on possibilities of the certain specialists \\
\hline
\end{tabular}


Introduction of technologization in marketing should mean a transition from certain uniqueness, personality, professional skills of marketing specialist to the system and predictable process. [18] This saves time and allows you to attract specialists of lower qualifications to work and therefore save on wages, to predict the result. This position makes it possible to compare marketing activities based on individual skills, with activities obtained as a result of technologization

\section{Conclusion}

Thus, such notion of "marketing technologies" should be considered as an interconnection of means, methods and processes, the need of which will have a targeted impact on the market environment, and marketing activities realized in practice. [19] The technology, as a scientific discipline, is based on the principle of decomposition of the process into its component elements and parts, in other words, patterns from which you can gather any new processing chain, providing "programming" of the entire process of marketing, using a sequence of actions to ensure the desired result [20]. Splitting of the technology into elements is necessary to emphasize patterns implemented in marketing technology that should be reproduced. This feature will allow wider use of the technology, which distinguishes a technological approach from other ways of organization of marketing activities.

Each element in the marketing in the construction sphere is met by certain marketing techniques that emphasize the specificity of this type of activity, and correspond it according to the parameters of flexibility and possibility of formalization. In essence, the specificity of technologization of practical marketing activities is focused on the development of comprehensive programs of creation, production and realization of the construction products, works and services in selected segments. [21] We can conclude that the when developing integrated marketing programs (plans) and taking into account the orientation of the organization for the future it is necessary to use marketing technologies that allow the construction organization to execute its strategic, tactical and operational plans.

\section{References}

Bagiev, G.L., Tarasevich, V.M. \& Ann H. (2008). Marketing (p.703). M.: Publishing house "Economy".

Marketing technologies. Retrieved from: http://biznestoday.ru/mark/640-tehnologii-marketinga.html

Schwalbe, H. (2013). Marketing practice for small and medium-sized enterprises (p. 317). M.

Nozdryova, R.B. (2011). Marketing: how to win in the market (p. 327). M.: Finance and Statistics.

Bleherman, M.H. (2008). Flexible production systems (Organizational-economic aspects) (p.95). M.: Economics.

Grakhov, V.P. (2011). Methodology of marketing management in the investment and construction sector. PhD thesis. SPb.

Sushko, U.K. (2010). Formation and development of marketing of enterprises in an integrated construction complex of the region. PhD thesis. Ekaterinburg.

Nozdryova, R.B. (2011). Marketing: how to win in the market (p. 327). M .: Finance and Statistics.

Mazilkina, E.I. (2011). Marketing in industries and spheres of activities (p. 333). M.

Suleymanov, M.M. (2005). Perfection of marketing activity of the enterprises of the building complex. PhD thesis. Makhachkala.

Asaul, A.N. The phenomenon of the investment and construction complex or construction complex is preserved in a market economy of the country. Retrieved from: http://www.aup.ru/books/m65/

Patsyuk, E.V. (2013). The complex of marketing at the enterprises of construction materials industry. PhD thesis. Volgograd.

Alekhina, E.S. (2010). The development of marketing technologies in the service sector of the region. PhD thesis. Shakhty.

Nagapetiants, N.A. (2012). Marketing in industries and spheres of activities (p. 272). M.

Pirogov, V.I., Zavyalov, S.K. \& Mukushev, G.R. (2013). Technologisation - the way to improve management of enterprise. Russian economic journal "ECO", 5.

Porter, M. (2012). The competition (p. 608). M.: "Williams".

Semenov, I.V. (2013). Marketing strategy of organization. Marketing, 2, 112-123.

Sergeeva, S.E. (2010). Effective marketing - the key to the success of the company. Marketing in Russia and abroad, 2, 114-120.

Khrutsky, V.E., Korneev, I.V. \& Avtukhova, (2012). Modern Marketing (p. 256). M .: Finance and Statistics.

Solovyov, B.A. (2012). Marketing (p. 381). M .: UNITY-DANA.

Solovyov, B.A. (2012). Marketing Management: 17-modular program for managers "Management of the organization development". Module 13. M .: "INFRA - M". 